\title{
LA FILOSOFIA DEL ARTE EN EL PORFIRISMO \\ (La obra de Manuel Sales Cepeda)
}

Por Raúl Cardiel Reyes

Es común la idea de que el introductor del estudio de la estética en México fue el maestro Antonio Caso; opinión que sostuvo y divulgó Samuel Ramos, especialmente en el estudio que le dedicó en 1952, al ingresar como miembro de número del Colegio Nacional:

Antes de Caso - dice Ramos en aquella ocasión- puede decirse que la estética no existía, en México y quienes tenían noticia de ella no le concedían la categoría que merece dentro del conjunto de las disciplinas filosóficas. Las otras partes de la filosofía de más renombre, como la lógica, la metafísica, la ética, etcétera, figuraron en nuestros estudios desde la época colonial. Por lo que concierne a la estética, puede afirmarse que Caso es de un modo absoluto el iniciador de su estudio en la historia de la filosofía en México. ${ }^{1}$

Sin embargo, uno de los primeros que contradijo esta opinión, tan generalizada en nuestros medios académicos, ha sido el maestro Antonio Castro Leal. En su estudio "La estética en México" de 1961, dice lo siguiente:

La afirmación es inexacta porque ya en 1905 Diego Baz había publicado en la ciudad de México unas nociones de estética - La belleza. y el arte- que trataban en su primera parte los problemas especulativos generales y en la segunda, su aplicación a las diversas artes. ${ }^{2}$

Un poco más adelante, en ese mismo estudio, agrega:

José María Vigil observa en el prólogo (que hizo para el libro de Diego Baz) que "entre la copiosa cantidad de trabajos que se han publicado en nusetro país, sobre muchos de los distintos ramos que comprende la instrucción pública, no había aparecido hasta ahora ninguno que sepamos relativo a la ciencia filosófica designada con el nombre de estética"... Ignoraba Vigil -sigue diciendo Castro Lealque Manuel Sales Cepeda había publicado en Mérida en 1896, unos estudios estéticos que, en poco más de doscientas páginas, trataban en forma sistemática - acaso por primera vez en México- los problemas de la estética.

1 Samuel Ramos, Estudio de estética, 1963, p. 286.

2 Sobretiro del Colegio Nacional, 1962, p. 93 
Estas dos obras son en realidad los primeros tratados de estética en México. Pueden señalarse estudios sobre la estética en general -como introducciones a temas específicos sobre algún arte en particular-, como las consideraciones que el licenciado Juan Nepomuceno Cordero hace en el quinto tomo de su obra La música razonada, de 1897, o los "Apuntes de estética" de don Porfirio Parra, el ilustre filósofo positivista, que empezó a publicar y dejó sin terminar en la Revista de México de 1890 , de todo lo cual da también debida cuenta el maestro Castro Leal.

Debido a las cuidadosas diligencias de nuestro amigo el licenciado Carlos Canto López, vecino de Mérida, Yucatán, hemos podido allegarnos un ejemplar del libro de don Manuel Sales Cepeda titulado: Estudios estéticos y entretenimientos literarios, que publicó el año de 1896, en esa ciudad en la Imprenta Loret de Mola.

El análisis de la obra de Sales Cepeda permitirá enterarnos de los criterios estéticos que privaban en la atmósfera intelectual del régimen de Porfirio Díaz, cuando se acercaba el final de siglo xIx. Lo significativo de su obra, como se verá del resumen que en seguida presentamos, es que expresa muy bien el sentido general de las tendencias intelectuales de la época.

Al parecer nació en alta mar, cerca de las costas de Yucatán, en barco, frente al Puerto Sisal, de nacionalidad mexicana, el 14 de noviembre del año de 1854. Pasó su infancia en la pequeña Villa de Motul, Yucatán, pero pronto pasó a la capital del Estado, en donde hizo sus primeras letras en las escuelas de la maestra Salomé Bolio y del profesor Juan González Arfián. Ingresó al Instituto Literario del Estado, hoy Universidad Nacional del Sureste, en donde terminó sus estudios de bachiller en 1870, obteniendo un nombramiento de Profesor de Matemáticas y Filosofía, lo que muestra que sus prendas intelectuales eran ya notorias a su corta edad. Se graduó de ingeniero topógrafo en el instituto y posteriormente inició y terminó la carrera de leyes, en la cual, sin embargo, no llegó a titularse.

En el año de 1882 llegó a ser director de la Escuela Normal del Estado y, posteriormente, del propio Instituto Literario del Estado.

Innumerables fueron las generaciones y los alumnos a los que sirvió de guía intelectual y moral. Tenía gran prestigio por su bonhomía, su vasta exudición. En el año de 1911, a los 56 años de edad, se jubiló en sus actividades docentes. Sin embargo, todavia en el año de 1923 fue 
designado consultor general de Educación. Falleció el año siguiente de 1924, en la propia ciudad de Mérida.

Cultivó el periodismo y fue director de algunas revistas pedagógicas como El Escolar y la Revista Peninsular. Escribió fundamentalmente sobre filosofía estética, y tradujo la obra de Próspero Fochat: Manual de filosofia positiva. Publicó unas "Misceláneas" y un libro que en su tiempo fue muy leído y aplaudido: De ayer y hoy, publicado en Mérida en 1909.

Autor dramático escribió varias obras, entre ellas: Pagar la lengua, Estrategia, El Dios de nuestros dias, Dorada infamia y Entre infames. En el tercer centenario de la aparición del Quijote intervino en un concurso convocado en Mérida, en el cual obtuvo el primer lugar con un ensayo titulado: El amor en el "Quijote". Es interesante recordar, finalmente, que en el año de 1899 hizo un viaje a París, como representante de Yucatán, a la Exposición Universal que se celebraba entonces en aquella ciudad. ${ }^{3}$

La obra de Sales Cepeda se compone en realidad de dos partes. La primera titulada "Estudios estéticos", de 199 páginas, forma la estética de que nos ocuparemos; la segunda, denominada "Entretenimientos literarios", consta de 300 páginas, se integra con veintisiete comentarios sobre sucesos literarios de su ciudad y temas diversos. Remata el libro un ensayo titulado: “¿El arte por el arte?”, de treinta páginas, que es Ia continuación de sus "Estudios estéticos".

Su primer capítulo titulado “¿Qué es la estética?”, intenta definir esa disciplina filosófica y señalax su problemática, lo más rigurosamente posible.

Sales Cepeda distingue tres disciplinas filosóficas fundamentales, que se ocupan de sendos campos de la cultura, a saber: la ciencia, la moral y el arte. A esos tres campos, corresponden tres ideas, conceptos fundamentales: lo verdadero, lo bueno y lo bello:

Cuando la filosofía encamina el pensamiento hacia la verdad, que es el objetivo de éste, se llama lógica. Cuando guía a la voluntad humana hacia su norte, que es el bien, se apellida moral. Cuando, por fin dirige el sentimiento y la imaginación hacia su ideal, que es la belleza, tiene el nombre de estética. ${ }^{4}$

A la belleza aspira y por la belleza respira el arte... Cabe pues una ideología de la belleza, una filosofía del arte, tan legítima como las filosóficas ciencias de lo verdadero y de lo bueno.

3 Diccionario Porrúa, "Historia, Biografía y Geografía de México", 1976.

4 Op. cit., p. 6 . 
Fue Víctor Cousin, el filósofo francés del eclecticismo clásico, quien estableció esas tres ciencias filosóficas fundamentales en su obra: De lo verdadero, de lo bello y del bien, de 1858. De ahí en adelante, esta división tripartita haría fortuna y se conservaría hasta muy entrado nuestro siglo.

Así como la lógica nos proporciona un criterio para discernir la verdad, y la moral para distinguir lo bueno, asi la estética ha de servir para dar un criterio sobre la belleza -criterio que, se apresura a afirmar Sales Cepeda, se funda en el gusto o la razón estética.

Por lo mismo, la estética parte de la subjetividad humana, del sentimiento y la emoción de la belleza. No se ha de buscar lo bello fuera de las cualidades específicas que caracterizan al espíritu, a la conciencia que capta esa belleza, sino que es a partir de su idea captada por el hombre, como la estética ha de llevar a cabo sus investigaciones filosóficas.

Sin embargo, Sales Cepeda piensa en una estética no sólo meramente descriptiva que nos haga plenamente conscientes del sentimiento de lo bello, sino también en una estética normativa que dicte leyes a la belleza y deduzca preceptos para el arte. Esta misión de la estética de llegar hasta el conocimiento de lo bello, para determinar sus leyes y sus normas, coloca a Sales Cepeda en la corriente del renacionalismo, que siempre sostuvo la capacidad de la razón para penetrar en la naturaleza más intima y recóndita de la belleza y determinar sus cualidades y sus características más esenciales:

Como la verdad y el bien, la belleza tiene sus leyes. Como la Ciencia y la Virtud, el arte tiene sus preceptos. Escudriñar las leyes de lo bello y depurar los preceptos del arte. He ahí definida la misión de la Estética. ${ }^{5}$

Sin embargo, donde verdaderamente se comprueba que Sales Cepeda concebía con gran amplitud el estudio de la estética es en la matizada exposición que hace de la problemática de esta ciencia. Aunque de hecho en su obra no despliegue el análisis de todos los temas que él piensa constituyen la estética, de cualquier modo el panorama que presenta muestra la gran perpectiva en que concebía la filosofía del arte.

Sin que esto lo manifieste de una manera patente, la estética, en términos generales, le parece una reflexión filosófica sobre tres temas:

ธ Idem, p. 7 . 
DOI: http://dx.doi.org/10.22201/iie.18703062e.1977.47.1087

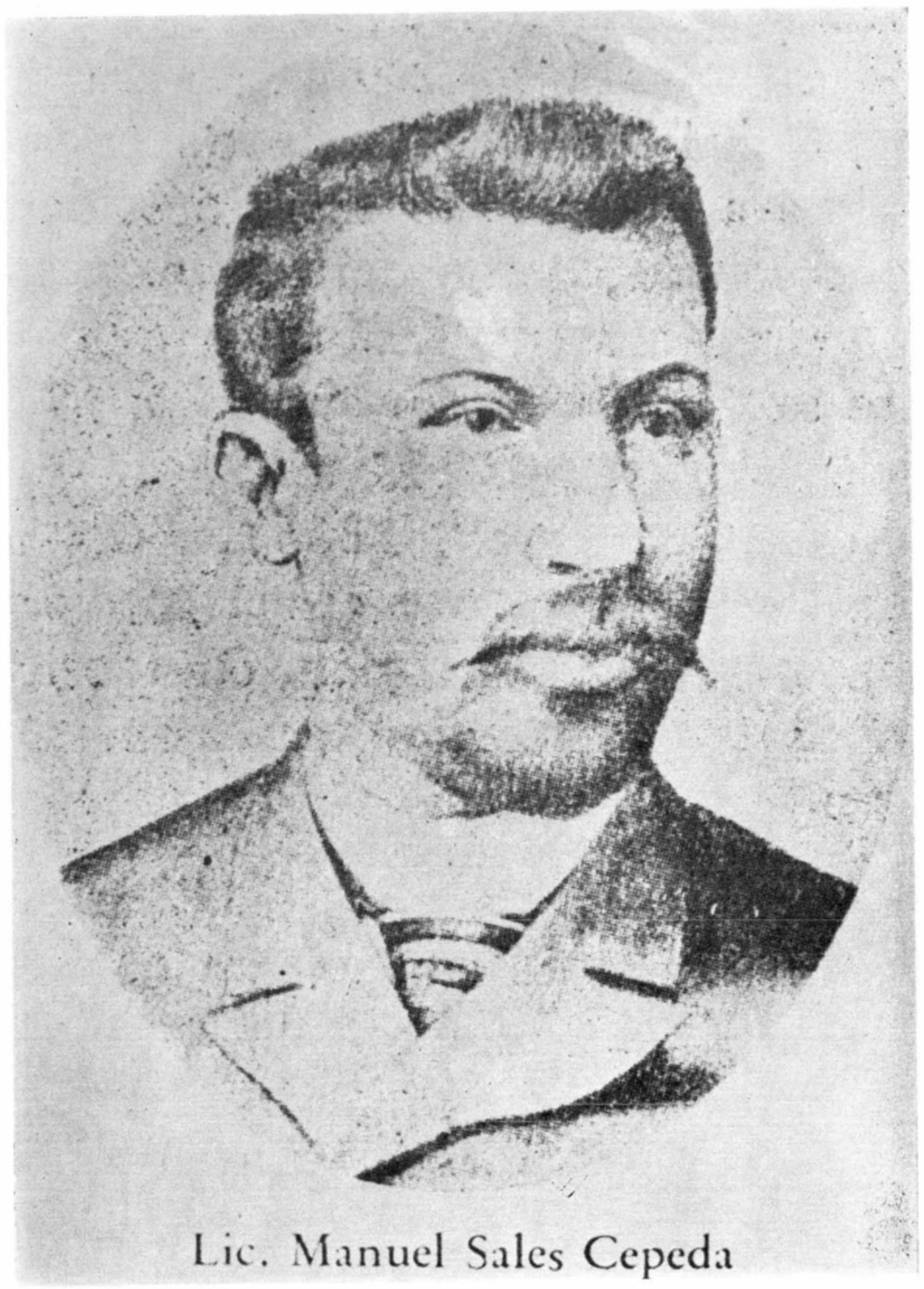


DOI: http://dx.doi.org/10.22201/iie.18703062e.1977.47.1087

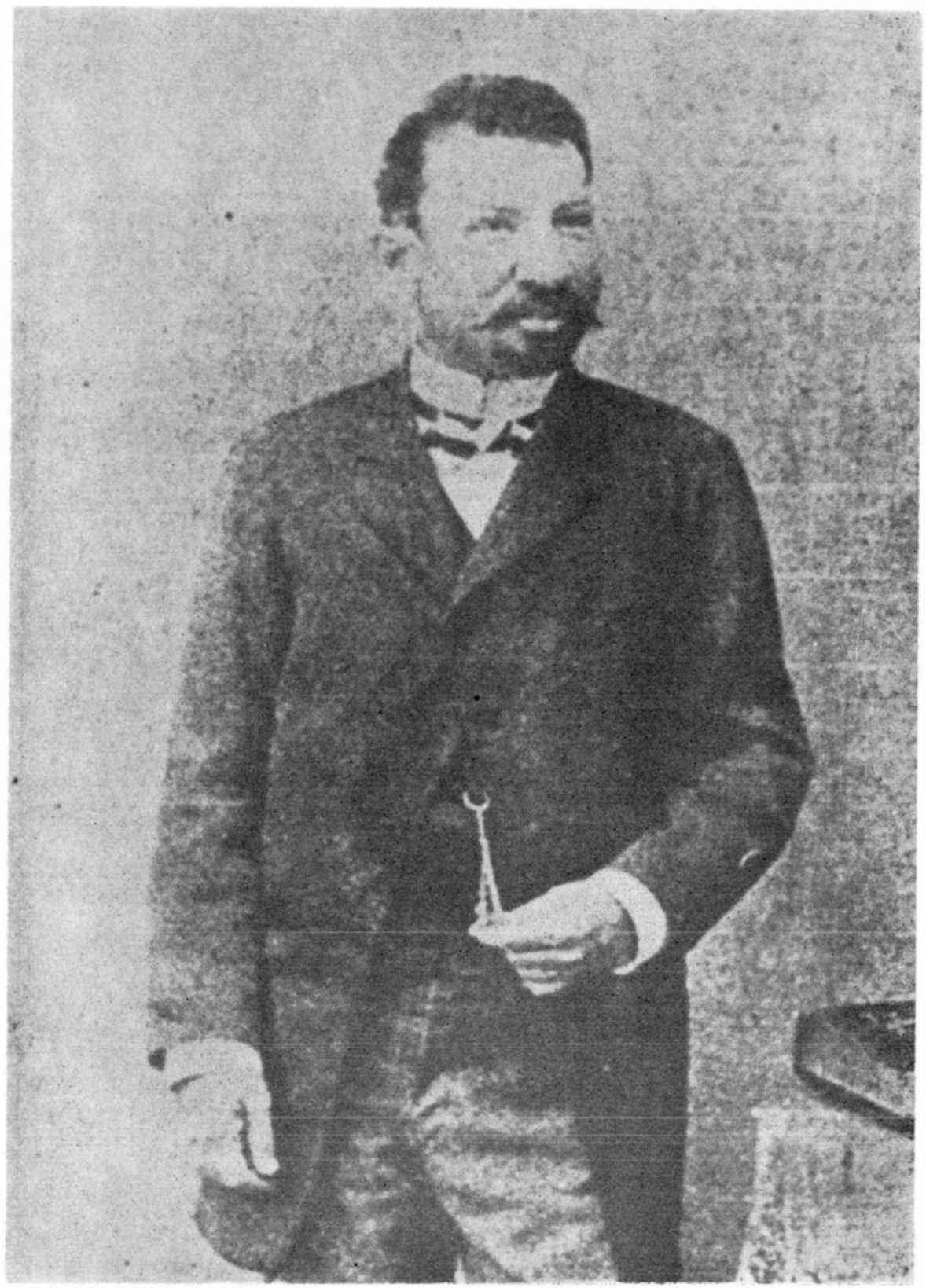


lo bello en sí, en la naturaleza y en el arte. La idea de lo bello en sí, más que un punto de partida, parece un término final al que se llega después de que el artista ha desplegado todas sus facultades y profundizado sus propias experiencias.

E1 primer tema de la estética le parece, por lo mismo, el estudio de la idea y el sentimiento de lo bello -nótese desde luego que no separa nunca lo intelectual de lo sentimental, pues en la naturaleza de lo bello se halla el que sea al mismo tiempo algo captado por el pensamiento y el sentimiento. El estudio de lo bello ha de ocuparse de su génesis, su carácter y su naturaleza. Problema especial lo constituye el analizar la emoción estética y determinar que le es propio un placer fino y delicado, diferente por su naturaleza, de los demás placeres de los cuales se distingue claramente.

El siguiente tema podría designarse como los diferentes conceptos de lo bello, entre los cuales clasifica el tema de lo sublime -convertido en problema fundamental de la estética desde los remotos tiempos de Longino-; además, los conceptos de lo maravilloso, lo fantástico, lo gracioso, lo cómico, todo lo cual constituye el contenido y la gama de las diversas emociones de lo bello.

No podría faltar en esta problemática de la estética la discusión de la verdadera naturaleza del arte,

las eternas cuestiones del idealismo y del naturalismo, para saber si ha de ser el arte un reflejo del espíritu en la naturaleza o de la naturaleza en el espíritu, si el arte debe copiar la naturaleza tal como impresiona la cámara oscura del fotógrafo o como es capaz de embellecerla e idealizarla el mágico prisma del artista. ${ }^{*}$

La estêtica ha de dilucidar si establece, dogmáticamente, los cánones inconmovibles e invariables de la belleza o el artista ha de gozar de plena libertad para encontrar, por si mismo, los medios que considere más expeditos para desplegar "su inspiración y su genio"."

Plantea luego un asunto fundamental; lo que podria llamarse ahora el criterio del arte. ¿En quẻ consiste el arte? ¿Cuáles son sus características esenciales? ¿Consiste el arte en pensar o sentir? ¿Radica en la forma o en el fondo? ¿Es la armonía del todo sobre las partes, la unidad sobre la diversidad? A todos estos puntos ha de llegar oportunamente la reflexión de Sales Cepeda.

6 Idem, p. 8. 
Capitulo esencial es lo que se denomina ahora el valor del arte. El arte puede considerarse un fin en sí mismo o simplemente un medio para otras finalidades más altas. El arte ha de servir para ilustrar la ciencia, los fines más altos de la sociedad o la civilización o tiene su finalidad en sí mismo, adoptando el lema, entonces famoso entre los románticos, del arte por el arte.

La estética ha de ocuparse, por otra parte, del proceso de la creación artística misma - lo que ahora se denomina la estética subjetiva-, los factores y elementos que intervienen en la producción de la obra de arte, como el gusto, la imaginación, el sentimiento, la inspiración, el genio.

Señala Sales Cepeda un tema básico de la estética, que ahora llamaríamos la axiología del arte: el análisis del valor estético mismo. ¿Qué relación guarda la belleza con lo verdadero y lo bueno? ¿Es la belleza un instrumento de la verdad y la bondad? ¿Tiene, pese a todo, caricteres propios que lo independicen de los demás valores?

Finalmente, cierra esta excelente exposición problemática lo que constituye la historia de la estética. "La estética o filosofía de lo bello es tan antigua como la de lo verdadero y de lo bueno." Platón y Aristóteles expusieron excelentes ideas sobre la belleza y el arte. Más tarde, en la cultura romana, destacan Horacio, de quien hace repetidas menciones, y Longinos, amén de otros ideólogos y preceptistas ilustres que ya no señala por sus nombres.

Cuando Baumgarten, en el siglo xvir, llama estética a esta disciplina filosófica sólo encuentra el nombre, pero de ninguna manera a la ciencia que tenía ya venerable antigüiedad. No deja de señalar Sales Cepeda lo inapropiado de la denominación "estética", término que sólo quiere decir "teoría de la sensibilidad", sentido que tomó el filósofo español Jaime Balmes al darle este nombre a su estudio sobre los cinco sentidos, en el cual no entra para nada el estudio de lo bello. Sin embargo, dice Sales Cepeda, "la ilegítima acepción está ya consagrada ... Al fin y al cabo... le nom ne fait pas-la chose". 7

Esta problemática de la estética presentada por Sales Cepeda, en las primeras páginas de su libro, caracteriza muy bien las limițaciones de esta disciplina, en las postrimerías del siglo xIx mexicano. Indica los temas fundamentales de una filosofía del arte, apenas se insinúa lo que se llamaría ahora una psicología del arte, en tanto que una sociología estética está ausente de sus páginas. La parte subjetiva, dedicada a la

TIdem, p. 11 
creación artística, se halla dominada por la actitud del filósofo y preceptista, apenas aparecen los análisis propiamente psicológicos.

La historia de la estética es aún muy pobre. Llama la atención que no se haya señalado a Kant - del que no obstante hace algunas referencias, o a Hegel, a quien cita una vez-y las teorías de Hipólito Taine o Spencer, que entonces se encontraban en boga.. La actitud racionalistapreceptista parece dominar sus reflexiones.

El estudio de las diferentes artes, como la arquitectura, la escultura, la pintura, la música, la literatura, no ocupan lugar especial. Al final del capítulo destinado a definir qué es el arte, trata de las diversas artes para concluir que la más alta y perfecta de todas ellas es la poesía, que se acerca más al pensamiento y la reflexión, a la naturaleza propiamente intelectual del arte, en tanto que las artes plásticas se resienten de un sometimiento especial "a la esclavitud de la materia"; la música, aunque se libera más de la materia, es aún demasiado vaga. La supremacía de las artes corresponde, por lo mismo, a la literatura, en ella a la poesía, que muestra finalmente en sí misma todas las excelencias de que es capaz el arte en su más alta expresión. Sin embargo, a través del libro, los ejemplos se toman de las artes plásticas, del teatro y de la poesía, principalmente, para ilustrar las meditaciones sobre los problemas estéticos.

En el capítulo dedicado a definir la belleza, Sales Cepeda expone algunos de sus criterios fundamentales. Aunque la belleza es una idea pura, clarísima como la luz, es, sin embargo, indefinible.

"Lo bello para cada quien es lo que agrada o deleita o produce en su alma una emoción simpática. Enhorabuena que no halla eternos arquetipos ni platónicos ideales." 8

La naturaleza es ante todo la maestra de la belleza. Lo bello natural parece ser la fuente y el origen de los sentimientos de belleza que forman al artista. Las campiñas de verdor sonriente, el cristalino arroyo que esmalta la pradera, el susurro blando de las auras, el trinar alegre del pajarillo. "todos estos aspectos que nos brinda la naturaleza inspira a cada paso al mismo tiempo, la concepción y el sentimiento de la belleza".

Una serie de interrogaciones le permiten hacer desfilar, poco a poco, todas las teorías que han intentado definir la belleza, en cualidades objetivas, en aspectos reales en donde se supone pueda residir:

8 Idem, p. I4. 
¿Nacerá la belleza de tales o cuales proporciones, perfiles, formas o colores? ¿Nacerá del orden, de la simetría? ¿Nacerá de la armonía o de la variedad en la unidad? ¿Nacerá de la perfección o bien de la identidad de la forma y de la idea, como Hegel opina? ¿Nacerá de la utilidad? ¿Nacerá sólo del hábito, de las aficiones y será una cosa siempre relativa? ¿Será la belleza hija de la verdad? La belleza son todos estos diversos aspectos de la realidad y tal vez algunos más. Mas lo que hay de cier to es que lo bello tiene, como lo verdadero y lo bueno, fuentes varias y que hay diferentes órdenes, fases y matices de lo bello. La Naturaleza es manantial innagotable de la belleza. ${ }^{9}$

Pero si la belleza reside en esos múltiples y variados aspectos de la naturaleza, que se han resumido en las interrogaciones que su sentido suscita, sólo el espíritu del hombre, su sensibilidad, su inteligencia, es capaz de sentirla, descubrirla, vivirla. "Sólo la organización bien dotada del hombre, percibe y siente la belleza." 10 Pero aun en los propios hombres se dan diferentes grados del sentimiento de la belleza, no sólo porque unos la sienten con mayor intensidad que los otros, sino porque los temperamentos y caracteres individuales descubren diferentes géneros de la belleza, ya la que se da en la pintura o la escultura, ya la que aparece en lo sublime, lo gracioso o lo cómico. "La belleza es, pues, cual piedra filosofal que se saca de todo, pero que reclama el mágico alqui. mista." 11

Al definir el arte se aclara que existen, una junto a la otra, la belleza natural y la belleza artística. La primera son todas las cosas que el hombre siente y reconoce como bellas en la naturaleza. La segunda es la belleza creada por el hombre, la belleza que agrega y añade a la belleza natural. De este modo, se pueden contraponer lo bello natural y lo bello artístico.

Mas cabe preguntar si la capacidad del hombre para hacer arte significa que puede crear algo nuevo, algo que no haya existido antes en la naturaleza. La respuesta es clara y obvia. El artista no crea realmente nada. "El artista transforma, perfecciona, armoniza, crea un nuevo mundo de belleza, es cierto; pero es la misma naturaleza que se muestra en el espíritu humano, evolucionando, concentrando lo bello... ${ }^{12}$

Primero, el artista recibe de la naturaleza la idea de lo bello y luego le devuelve en sus creaciones lo bello de la idea Primero, entiende lo que

9 Idem, pp 16 a 19

10 Idem, p. 21

11 Idem, p. 22

12 Idem, p. 24. 
siente o hace inteligible lo sensible y luego siente lo que entiende o hace sensible lo inteligible. Primero, idealiza o espiritualiza la materia, y luego plastifica o materializa el espíritu. Píntase, en fin, primero la idea del cuerpo o de la forma; pinta, después la forma o el cuerpo de la idea... Y eso, no más que eso, es el arte. Encarnar en lo tangible real lo intangible ideal. Volver lo subjetivo objetivo, material lo inmaterial, corpóreo lo incorpóreo; hacer una imagen visible del invisible pensamiento trocar en palpable realidad el impalpable ensueño... devolver al mundo de la belleza lo que de la belleza del mundo escondíamos... en fin, como se ha dicho, hacer sentir a la inteligencia y entender a los sentidos: he ahí la grande, la noble, la hermosa misión del arte. ${ }^{13}$

En forma clara y precisa Sales Cepeda expresa en las líneas anteriores el credo que podríamos denominar del neoclacisismo, la exaltación de las formas naturales, orgánicas de las cosas, la captación por la sensibilidad y la inteligencia de la forma perfecta, completa, plena, que subyace en todos los objetos que ofrece la realidad. La sensibilidad y la inteligencia ascienden desde las cosas hacia las ideas que constituyen su esencia, para después descender desde el limbo de las formas puras hacia su incorporación, materialización en las obras de arte. Es una imitación pero no de la naturaleza tal como se ofrece a los sentidos, sino de la naturaleza en su forma esencial, en sus estructuras puras y eternas, en donde el intelecto y la sensibilidad hallan el goce, el deleite que sólo la perfección de la forma puede darles.

Por eso mismo esta definición del arte conduce, en forma lógica, al problema de su naturaleza, que ocupa una de las partes centrales, más importante, de la obra de Sales Cepeda.

La filosofía pregunta: ¿Es el espíritu dueño y señor de la materia o la materia reina y señora del espíritu? Y la estética cuestiona: ¿Debe la naturaleza ser esclava del arte o el arte esclavo de la naturaleza? En una palabra, ¿debe el arte imitar servilmente a la naturaleza? ${ }^{14}$

Ante estas preguntas cruciales, Sales Cepeda encuentra tres posiciones diferentes. Ante todo la del realismo puro, intransigente. Quiere un arte copia fiel de la realidad, que la presente tal como es, descarnada, desnuda, con todas sus deformidades, sus monstruosidades, sus fealdades, aunque se abisme en lo abyecto, lo conallesco o lo soez

13 Idem, pp. 25 y 26

14 Idem, P. 39 
Otra posición es la del naturalismo "intermediario" o verismo, que desea un arte que copie sólo la naturaleza bella, pero no la fea. En tanto que el realismo muestra las llagas, el naturalismo las cubre con un velo.

Hace honor a la perspicacia y ciencia de Sales Cepeda, el haber distinguido dentro del realismo el giro que el fin del siglo xix daba hacia lo psicológico, hacia la realidad, no como lo objetivo y exterior sino como lo subjetivo e interior. Refiriéndose a algunos críticos contemporáneos, que no cita, dice:

Llaman naturalismo al arte inspirado en la naturaleza objetiva, digámoslo así, más que en la subjetiva; al arte inspirado en un fisiologismo fatalista, en el determinismo, en el materialismo filosófico, en fin, a. la escuela de Zolá, en una palabra . Por realismo entiende el arte basado en la observación de los fenómenos subjetivos o psíquicos más que en la de los materiales $u$ objetivos; esto es, el arte analizador que produce los más minuciosos detalles del alma, del yo, del ser moral; en suma, el psicologísmo escrupuloso de Balzac o de Bourget. ${ }^{15}$

Sin embargo, contra todos los realistas y naturalistas, se opone la tercera posición que llama del idealismo, en sus dos formas: el clasicismo y el romanticismo. En tanto que las dos primeras posiciones, el realismo. o naturalismo puro e intransigente y el naturalismo intermedio o verismo, buscan la mera copia de la naturaleza-una de lo teo y lo bello, la segunda sólo de lo bello,

el idealismo, en general, quiere que el arte sea una reproducción libre y no servil de la belleza; que sea una interpretación y no una copia; que tenga vida e inspiraciones propias que idealice, que fantasee, que cree, que si refleja y copia al mundo, lo copie y lo refleje, hermoseando y ennobleciendo el natural modelo, mirándolo tras el prisma de la belleza ideal; quiere en fin, que el arte corrija, depure, perfeccione, que le enmiende, por decirlo así, la plana a la naturaleza. ${ }^{16}$

A propósito de estas ideas de Sales Cepeda, no podemos menos que recordar al pintor inglés Reynolds, que en el siglo xvin dio la fórmula clásica de este concepto del arte en sus discursos:

La belleza y grandeza del arte consiste en ser capaz de ir más allá de todas las formas singulares, costumbres locales, particularidades de toda clase ... El pintor corrige a la naturaleza misma, a su estado imperfecto

15 Tdem, p. 43

16 Idem, p. 44 
por otro más perfecto. Su ojo es capaz de distinguir las deficiencias accidentales, las excrescencias y deformidades de las cosas. De sus figuras generales obtiene una idea obstracta de esas formas, más perfecta que su original. ${ }^{17}$

Dentro de esta escuela del idealismo distingue el clasicismo propiamente dicho, que cree en la fórmula de la perfección, en las normas invariables y eternas, en los dogmas perfectos, en los moldes definitivos. "Es el arte eterno, el arte inmóvil, el non plus ultra del arte." 18

En cambio el romanticismo es el rompimiento de las normas invariables; la libertad en el arte, para dejar el espiritu remontarse hacia las regiones más altas, para inspirarse en el absoluto ideal de la belleza. "Así, quiere que la materia, que el cuerpo, que la forma no exprese más que el espíritu; que el arte no refleje otra cosa que la belleza espiritual, ideal." 19

El clasicismo representa el idealismo pagano; el romanticismo, el espiritualismo cristiano. Entre ambas escuelas, se ha desatado una lucha encarnizada. Por un lado romanticismo revolucionario de Víctor Hugo y sus discípulos; por el otro el arte conservador, el preceptismo de Horacio y de Boileau; la imitación servil de Racine y de Molière.

Aunque se ha criticado al romanticismo su desmesurado subjetivismo o lirismo -el sentimentalismo exagerado que degenera a veces en lo cursi y en la sensiblería distinguiéndose por el contrario el clasicismo, por su sobriedad y mesura-, Sales Cepeda piensa que ambas escuelas difieren por su distinto concepto de la belleza: el clasicismo campea en el sentimiento de lo bello; el romanticismo desborda en la región de lo sublime.

No podríamos decir si Sales Cepeda haya conocido o tenido noticias del famoso tratado de juventud de Kant, Observaciones sobre el sentimiento de lo bello y lo sublime, en donde el famoso filósofo sorprende por su amenidad, gracia y fino estilo literario. En todo caso ese pequeño ensayo hizo célebre la distinción entre lo bello y lo sublime -había entre ambos como una gradación del sentimiento de la belleza. Lo bello era la belleza tranquila, noble, mesurada; lo sublime la belleza en sus más altas proporciones, desmesurado, trágico, terrible -aunque Kant no haya aceptado que lo monstruoso, lo desproporcionado, fuera de lo

17 Citado por Herbert Read, Filosofia del arte moderno. Londres, p. 76.

18 Idem, p. 44.

19 Idem, p. 45. 
natural, fuese cualidad de lo sublime, el desarrollo de este concepto terminó por abarcar también las monstruosidades.

El género romántico, al contrario, vive de la desproporción, de los contrastes, es desgarrador y tumultuoso. Todo lo profundizado engrandece, todo lo sublime, lo transfigura. Gusta de lo terrible, de lo misterioso, de lo infinito. Produce algo así como un conflicto entre el pensamiento y la imaginación. 20

Frente a estas dos tendencias fundamentales - por un lado el realismo, por otro el idealismo; queriendo uno copiar servilmente a la naturaleza, queriendo el otro expresar los valores propios del espíritu-, Sales Cepeda toma una posición singular, no quedarse con ninguna de esas escuelas, no porque las rechace sino porque las acepta a ambas. Hacer realismo o idealismo lo mismo da, puesto que, en el fondo, todo es la libertad del espíritu del artista para crear su obra. Debiera añadirse que hay dos extremos que le parecen inadmisibles y que se empeña en atacar y destruir, el realismo exagerado que cae en la simple copia fotográfica de la realidad y el realismo pesimista, determinista, fisiologista de Zolá, cuyas teorías estéticas expone y analiza, con cierto cuidado, para rechazarlas por contener una tendencia que le parece absurda.

$Y$ en este afán de Sales Cepeda de salvar al arte de ser una simple copia de la realidad, en este rechazo total de un realismo llevado a sus extremos, llega hasta formular una teoría del arte que se antoja demasiada avanzada para su tiempo y que, sin embargo, expone con toda claridad. Nos referimos a la teoría que considera el arte como una mera ilusión, tesis que en nuestro tiempo ha ilustrado brillantemente E. H. Gombrich en su libro Arte e ilusión, de 1960.

Le parece que el ideal del naturalismo, copiar la naturaleza, es un propósito imposible de realizar.

¿Qué pincel, ni qué paleta, ni qué arte, siquiera sea de magia, puede trasladar al lienzo la cabellera fúlgida, radiosa, deslumbrante del naciente rey del día? $\mathrm{Y}$ ¿cómo la pintura, la poesía, pese a su verbo, no es impotente mil veces para traducir del natural la pesadumbre infinita del dolor o la embriaguez voluptuosa de la dicha, la fiebre del entusiasmo o del fuego de la pasión?... Hay que desengañarse pues, arte quiere decir reflejo o representación, pero convencional, ficticia, ilusoria, no representación, ni trasunto ni copia verdadera. Es la verdad condicional y relativa; no la verdad incondicional y absoluta. Las imágenes, hipér-

20 Idem, p. 49 
boles, metáforas y demás vuelos artísticos, gala y ornato del lenguaje, ¿qué son sino verdades mentirosas, de valor entendido? 21

Pero lo más curioso es que justamente el argumento de Gombrich, el que el espectador vea en un lienzo una montaña y no simplemente una tela coloreada, lo expone Sales Cepeda con toda claridad. "Y la pintura tiene sus convenios para representar la luz, sin que lo sea... y todas las artes lo tienen, porque sin eso dejarían de ser artes." 22

Una prueba de la libertad del arte frente a la realidad - la capacidad de representar lo que no es real, lo que desborda los límites de la naturaleza- es la existencia del arte fantástico, uno de cuyos ejemplos analiza, en sus crónicas literarias que denomina Entretenimientos literarios, al comentar la novela fantástica de Teofile Gautier, Avatar. "Ya el artista no quiere pintar lo natural ni lo ideal sino lo fantástico, eso es su sueño, quimeras y visiones. Concedido. ¿Por qué no? Arte será y muy arte si hay belleza." 23

Sin embargo, en otros párrafos parece contradecir su propia opinión al tratar de concluir sus razonamientos: "Lo esencial en el arte, es la belleza. Lo bello es el alma del arte y el arte del alma . . . Lo repetimos. Para nosotros si el arte no embellece lo natural, no es arte." 24

Su criterio parece oscilar entre una total libertad del arte, que le permita crear sueños y quimeras, salirse de lo real y un mesurado equilibrio entre el realismo y el naturalismo, entre un realismo que siempre tendrá a la naturaleza como su materia y un naturalismo que siempre querrá idealizar, sublimar, espiritualizar, lo natural.

En el capítulo final de su estética, “¿El arte por el arte?" vuelve a plantear de otro modo la naturaleza propia de la actividad artística y aunque llega a conclusiones claras sobre el tema, no parece, sin embargo, identificarse con las meditaciones que hemos transcrito antes.

En ese capítulo, comenta la sentencia "el arte por el arte" atribuida a Victor Hugo, pero que este escritor rechazó repetidas ocasiones, reconociendo, no obstante, haber proferido aquellas palabras sin verdadera intención de hacer una definición de la naturaleza del arte.

Víctor Hugo era partidiario, al parecer, de un arte al servicio de la ciencia y del progreso; de un arte subordinado a lo verdadero y a lo átil; de un arte, en fin, que fuese instrumento idóneo para apoyar las

21 Idem, p. 53.

22 Idem, p. 54

23 Idem, p. 54.

24 Idem, p. 57. 
nobles tareas de la civilización. Según Sales Cepeda, en las siguientes expresiones podría condensarse el credo estético de Víctor Hugo:

El arte por el arte puede ser muy bello, pero el arte por el progreso y por el bien es más bello aún. Soñar engendros fantásticos es muy hermoso y bueno; pero soñar la utopía es mejor y más hermoso ... El vidente, el soñador, el genio, no se pertenece; pertenece a su apostolado, Tiene una misión inmensa: ser guía del espiritu humano... En el punto a que la cuestión social ha llegado, el arte debe servir, debe ayudar a la ciencia. Las dos ruedas enormes del progreso deben girar al unísono... Lejos de ser estorbo, no es mal hallazgo para el poeta el deber. El deber tiene una severa semejanza con el ideal. Nivelar al pobre con el rico, al débil con el fuerte, al opresor y al oprimido, batallar por la democracia, por la libertad, por la civilización, iqué magnífico esfuerzo!, iqué sublime deber!... Como se ve -sigue diciendo Sales Cepeda- es imposible abogar con más inspiración ni más grandeza en favor del arte tendencioso y útil. ${ }^{25}$

Sales Cepeda define la cuestión con decisión y claridad. No puede aceptar lo que llama el arte tendencioso y útil y suscribe la posición de que el arte tiene un fin propio, que no se confunde ni con lo verdadero ni con lo útil, que es la belleza. Gree que no altera la naturaleza del arte el ocuparse, si quiere, de apoyar y defender las grandes causas; pero afirma que esto no significa que se niegue al arte, que sólo se propone "el solaz del corazón, el halago de la fantasía o el divertimiento del espiritu".

Juzgamos - dice- que tanto pecan de injustos los que pretenden que la poesía no pase nunca de ser una pintura inconceptiva o un recreativo fantaseo ajeno a toda idea profunda o tendencia docente, como los que se aferran en negarle toda independencia y libertad y quieren convertirla en mero adorno-atavío de la moral y de la ciencia, en "la. formosa cobertura de la verdad", como dijo Santillana. ${ }^{26}$

E1 credo estético que Sales Cepeda pone en boca de Víctor Hugo, no hace sino repetir los principios fundamentales sobre la función social que el positivismo asignó al arte. Estas ideas las expresó con gran precisión, el pontífice de la escuela, Augusto Comte en su famoso ensayo Plan de trabajos científicos necesarios para reorganizar la sociedad, que la Universidad Nacional ha editado bajo el título de Ensayo

25 Idem, pp. 504 a 512.

20 Idem, p. 515. 
de un sistema de politica positiva. A la ciencia, dice Comte en ese trabajo, corresponde señalar la ruta que marca la marcha de la civilización; al arte corresponde hacer amar y hacer deseable las metas de la civilización indicadas por la ciencia.

Sin embargo, Sales Cepeda rechaza terminantemente el credo estético del positivismo, levantando frente a él el principio de la autonomía e independencia del arte, al sostener una finalidad que le es propia como la realización de la belleza.

Pero en el capítulo que ahora examinamos, Sales Cepeda avanza un paso más en su examen del tema central de la estética y por vez primera trata de encontrar una definición de la belleza.

La poesía... es la expresión o interpretación de la belleza, donde quiera que se sienta o conciba, por medio de la palabra sujeta a artística forma... el mérito capital de toda producción poética, en cuanto obra de arte, depende esencialmente de su forma... Dijéxase que la forma no es el cuerpo sino el alma de la obra... Así la forma es la creación, es la figura con que presenta el poeta el pensamiento o pasión que lo inspira; el ropaje con que engalana su idea, el acento original con que la canta. La forma encierra cuanto de vida, de fuego, de inspiración y de entusiasmo ha puesto el poeta en su obra y cuanto de pasión o inventiva introdujo para lograr su artístico propósito... En la verdadera poesía, el bien y la verdad deben subordinarse en lo absoluto a la belleza... En resumen creemos una vez más que el arte tiene en sí un fin exclusivo y propio: la realización o representación de lo bello; que la poesia bien puede recibir inspiraciones de lo verdadero y lo bueno, mas sin apartarse en la creación artística de su fin primordial; sin considexar el bien y la verdad como su final objeto." 27

Esta estética de la forma, tan vigorosamente expuesta por Sales Cepeda, no se compagina con la estética del contenido que expone al hablar de los géneros o contenidos de la belleza, al modo de la escuela hebartina, cuando trata, en sendos capítulos, de lo sublime, lo fantástico, la gracia, lo cómico, lo maravilloso. Estos temas tocan no tanto la forma del arte cuanto las cualidades propias de lo bello; es decir, los contenidos del sentimiento de la belleza.

Las indecisiones entre un arte que se propone idealizar la naturaleza y un arte que reclama su derecho a escapar de todo fenómeno natural e irrumpir en los reinos de lo fantástico y maravilloso, del ensueño y la quimera, esa vacilación entre una estética que se mantiene en los límites

27 Idem, pp. 515 y 532 
de lo objetivo y otra que tiende a plantear en lo subjetivo, ahondando en los caracteres psicológicos, revelan las tendencias artísticas contradictorias, las diversas estéticas de la época que pugnan por hacer salir al arte de sus cauces tradicionales.

Pero existen otras características por las cuales la estética de Sales Cepeda pertenece definitivamente al siglo xix y que la perfilan como una expresión espiritual, genuina del ambiente intelectual del porfirismo. Su sentido de lo universal, de lo general, en donde no hay lugar para singularidades nacionales - para peculiaridades de lo mexicano, de lo regional- sino las inquietudes meramente universales del arte, indiferentes a toda acotación particular nacional. Es significativo que en los repetidos ejemplos sobre los artistas y sus escuelas no aparezcan los mexicanos ni sus creaciones típicas. Salen a relucir Homero y Dante, Shakespeare, Milton, Ariosto, pero ninguno de los escritores mexicanos del momento o aun de un pasado más o menos cercano. Sólo una vez alude al Duque Job, a propósito de los fantasistas, colocándolo al lado de Gautier. No existe por lo mismo en la estética de Sales Cepeda ninguna conciencia de la nacionalidad ni ha dejado lugar para singularizar la interpretación artística producida a través de la historia de su propia nación. En su teoría de la estética, sólo tiene lugar el espiritu universal que cierne sus formas eternas sobre las singularidades efímeras y transitorias de pueblos y naciones que no alcanzan a dejar su impronta en las obras inmortales del arte. 